\title{
21. Seismic Shifts: The Canterbury earthquakes and public sector innovation
}

\author{
John Ombler and Sally Washington
}

The Canterbury earthquakes had a huge impact on government services. The scale of the 22 February 2011 event meant that many public servants could not access their damaged buildings, forcing many to work remotely from home or co-located in buildings that remained functional. Some departments deliberately redeployed staff to help where they were needed most, including to work with non-governmental organisations (NGOs) and in the community. The tenacity of those public servants and their commitment to serving the public, despite their own personal and family disruptions, were commendable. Sometimes the choice of where to work in the early days was determined on the basis of where there was functional plumbing.

Government departments with a presence in Canterbury were asked to document the impacts of the earthquakes on their staff and operations, and how they had responded to that disruption. Putting all those responses together produced a tome of A3 sheets that revealed some innovative approaches to public service delivery and design. When these examples were presented to ministers, they asked for more of the same, not only in Canterbury but also nationwide.

The earthquakes showed the agility and resilience of the public service in times of crisis. This will help our ability to be ready and able to respond to future crises. They also provided a 'perfect storm' for innovation. The innovative responses to the disaster revealed some new ways of working that offer lessons about how to improve public service design and delivery, not only in response to a disaster but in a business-as-usual context. The Canterbury innovations provide live demonstrations of what New Zealand's Better Public Services (BPS) ${ }^{1}$ program is trying to achieve.

This chapter discusses the Canterbury innovations and the lessons they offer for public service design and delivery. We argue that building innovation capability is an important component of future-proofing the state.

1 For a description of the Better Public Services program, including the Prime Minister's 10 Result Areas, see: <http://www.ssc.govt.nz/better-public-services $>$. 


\section{The Canterbury Innovations Project}

The State Services Commission (SSC) took the lead on a project to ensure the public sector took full advantage of the lessons from the Canterbury innovations. Key partners in that project are the Canterbury Earthquake Recovery Authority (CERA) and the Christchurch Government Leaders Group, comprising senior leaders from government agencies based in Christchurch. The project is now an integral part of the BPS program. It sits at the interface of two of the Government's top priorities (see Box 21.1) - delivering better public services and rebuilding Christchurch - and should contribute to the two economic priorities.

\section{Box 21.1}

\section{Government priorities}

- Responsibly manage the Government's finances

- Build a competitive economy

- Deliver better public services

- Rebuild Christchurch

The project provides early practical examples of BPS made real. Too often we tell agencies what to do without giving them guidance or shoot them down when they get it wrong. We need to also celebrate success and share examples of where they have got it right, including as a way to inspire other agencies to follow suit. The Canterbury innovations project is designed to

- showcase and sustain the innovations, draw the lessons from them and apply them, where appropriate, to business elsewhere

- promote Christchurch as an innovation zone, applying deliberate and coordinated capability to help drive the Christchurch rebuild, and to prototype models of service delivery and design for the rest of the country as demonstrations of BPS

- draw lessons from Christchurch to help build innovation capability across the state services.

\section{Showcasing Christchurch Innovations and Applying the Lessons Elsewhere}

The Christchurch innovations project began with four case studies demonstrating examples of innovative public service delivery and/or design emerging in response to the earthquakes. The organisations involved in the initiative, the value added by the initiative, what the innovation demonstrated in terms of 
better public services, its potential scalability and next steps for the initiative were the subjects of a report to cabinet and published case studies, which are all available on the SSC's website. ${ }^{2}$

The initial four case studies covered the following.

- The Canterbury District Health Board (CDHB) eShared Care Record View $(e S C R V)$ : A secure online system for sharing patient information between health professionals - invaluable in a disaster when paper records were irretrievable and access to usual health providers was disrupted. The eSCRV was co-produced by the $\mathrm{CDHB}$ and a range of private health providers, ensuring buy-in and that the service met the needs of users.

- Recover Canterbury: A joint venture between the Canterbury Development Corporation, the Canterbury Employers Chamber of Commerce and several government agencies including Inland Revenue, which supports earthquakeaffected businesses with advice, mentoring, referrals (to government as well as professional services) and grants. Users of the service report not knowing, or caring, whether they were dealing with public or private sector staffthey just recognised Recover Canterbury as a vital support and a successful brand.

- Justice Services Recovery: Including centralised court scheduling and the use of alternative facilities that enabled the maintenance of court proceedings despite significant damage to infrastructure. Co-location of justice agencies and community-based organisations is also being explored, building on agencies' shared experience at Ngā Hau e Whā marae following the earthquakes.

- Earthquake Support Coordination Service (ESCS): Co-production between government agencies and NGOs to provide support for families and households following the earthquakes.

The innovations were significant in their own right; but more importantly, they offer lessons for the future design and delivery of public services in New Zealand.

\section{Citizen/Business-Centric Service Design: Designing services around the user}

Citizen-centric service design — building services around people's needs — was a constant theme running through the case studies. Both Recover Canterbury and the ESCS used a tailored support model, with clients assessed on need and offered varying levels of support, from 'light touch' to full wrap-around

$2<$ http://www.ssc.govt.nz/christchurch-innovations $>$. 
services based on that assessment - a triage approach to service provision. Both examples provided a coordinated service with multiple access points; there was 'no wrong door'. The sustainability of these models and the cost and benefits in different policy contexts will need to be evaluated over time. They provide live demonstrations of channel strategies for providing services and information (online, telephone, in person, and so on).

Building services around citizen needs was a key theme of the BPS Advisory Group's report. ${ }^{3}$ The Christchurch experience will help inform options for BPS Results 9 and 10 aimed at improving government interactions with New Zealanders.

\section{Co-Production: Making the most of available capability}

The BPS Advisory Report argued that citizen/business participation is a powerful driver for delivering better services and value for money and that more use could be made of best-sourcing to drive improved performance in New Zealand state services. Christchurch provides practical examples of the value of co-production.

CDHB's eSCRV was the product of multiple stakeholders, public and private, coming together to design and agree on a mutually beneficial system (funded by CDHB). Recover Canterbury and the ESCS are further examples of co-production and tapping the best expertise available, whether public, private or community based, with funding and form following the desired function.

The ESCS demonstrated a new approach to contracting with NGOs, involving providing funding to backfill the roles of staff seconded into the ESCS rather than the standard 'contract-for-service' approach.

\section{Co-Location: The foundation for joined-up services}

Co-location and secondments to other agencies changed how public servants thought about their work and their operating environment. In Christchurch staff gained valuable insights from the opportunity to see how other agencies operate, and for those staff working in Recover Canterbury and the ESCS, a better understanding of the business and community sectors respectively. For example, interviews conducted with Inland Revenue Department (IRD) and Work and Income staff (Inland Revenue/Communications and Inquiry National Research Unit 2011) revealed that they now see joined-up government service

3 The advisory group's report is available on the SSC website: $<$ http://www.ssc.govt.nz/better-public-services $>$. 
as the way of the future. Despite differences in organisational culture and functions, they recognised similarities in customers and types of services and the potential to realise efficiencies by sharing information and facilities while providing clients with the best possible assistance available. The Christchurch experience confirms the value of co-location for frontline services and provides a practical example of how common results have the power to break down agency silos.

\section{Information Sharing and Use of Technology Drives Better Services and Improves Efficiency}

The Christchurch innovations show multiple examples of information sharing and the use of technology to drive better services, with improved outcomes as the driver and efficiency the by-product.

Faster treatment, less duplication of diagnostic procedures and reduced acute admissions are some of the efficiencies facilitated by shared access to patient records, without the associated cost of having to design a central database or replace existing IT systems in CDHB's eSCRV.

The ESCS shared client information (with a consent process) ${ }^{4}$ between government agencies and with the community partners involved. Recover Canterbury similarly involved sharing information across agencies. This facilitated faster and better referrals and better services to clients.

Centralised venue location, a centralised inbound calling function and text messaging were used to enable essential court services to be maintained following the earthquakes; the initiatives provided a practical application of work under way in the Ministry of Justice and are being fed into future justice sector planning.

We have stressed the need to maintain the enabling environment in Christchurch to support and to monitor the current and emerging initiatives over time. This is crucial for testing the sustainability of those innovations and future iterations and for assessing their ongoing value including in other contexts. Some might be appropriate to an emergency situation and the transition phase but have diminishing returns under business as usual. Moreover, agencies such as Inland Revenue deployed staff and resources into the emergency response

4 Sharing of personal information is allowed in emergency situations under the Privacy Act. The Privacy Commissioner communicated the Christchurch Earthquake (Information Sharing) Code 2011 (Temporary) to clarify the conditions under which personal information could be shared. The Privacy Commissioner has since commissioned research into the use of the code (<http://privacy.org.nz/christchurch-earthquake-informationsharing-code-2011-temporary/>), the results of which will feed into the development of a new code of practice applicable to any national emergency. 
in Christchurch that would need to be redeployed under business as usual. Agencies have been asked to monitor and evaluate the initiatives to assess how they can be applied to their business elsewhere. A further report to cabinet on sustaining innovation in Christchurch government services will be prepared in late 2012 .

\section{Christchurch as an Innovation Zone and a Harbinger of Better Public Services}

The need to build new infrastructure in Christchurch offers a once-in-a-lifetime opportunity to redesign government services and to test innovative models of service delivery. This should build on the lessons learned post earthquakes - for example, to maximise the opportunities for co-location and to design services around user needs. Several big opportunities stand out.

\section{Rebuilding Education Facilities in Greater Christchurch.}

The rebuilding of education facilities in Greater Christchurch offers a unique opportunity to test new approaches to governance, provision of school facilities and property (shared infrastructure/facilities with other community services), building on some of the interim arrangements introduced following the earthquakes, such as shared campuses and the use of portacoms for early childhood education. The focus for renewing the education network will be on strengthening the delivery of education including through sharing property and facilities and better transitions between learning stages, from early childhood to tertiary education. As in other service areas, the aim is to build back better rather than to simply replace what was there before.

\section{Office Accommodation for Government Services in Christchurch: Trialling Functional Leadership}

Government agencies' needs for new accommodation in Christchurch provide the opportunity to develop innovative accommodation arrangements that are both more efficient and galvanise cross-agency work seeded during colocation following the earthquakes. There are two key phases of work: securing government office accommodation for regional management and corporate support functions in the CBD rebuild, and a longer-term service delivery 
network (in-person public interface sites). Christchurch provides an opportunity to operationalise and test the value of functional leadership ${ }^{5}$ that is a major component of the leadership stream of the BPS program.

\section{Shared Front of House: Prototyping service transformation and BPS Result 10}

Decisions about the Government's overall property strategy provide a limited window to implement some different approaches to face-to-face service delivery in Christchurch. Evidence from existing initiatives in Christchurch, and from similar front-of-house consolidation in other jurisdictions, confirms that integrated government service delivery has benefits for citizens as well as for agencies. These models put citizens at the forefront; services are designed around meeting their needs efficiently and effectively. Moving from an agency-centred service delivery approach to a citizen-centred one requires consideration of issues such as the alignment of technology, work practices, business processes and employment agreements. There is a significant opportunity in Christchurch to experiment with different delivery models and to trial a number of shortterm options in the interim phase, before longer-term accommodation options are fixed. These opportunities allow for some prototyping of options for BPS Result $10 .^{6}$

\section{Justice and Emergency Services: Opportunities for co-location}

Police, New Zealand Security Intelligence Service (NZSIS) and Department of Internal Affairs (DIA) Fire Service, as well as ambulance and local government Civil Defence and Emergency Management (CDEM) are working together to co-locate and integrate some areas of service delivery into a shared campus in the CBD. It involves a rethink of infrastructure and property arrangements and an analysis of the synergies between agencies. Synergies between the justice sector and emergency services are sought through shared custodial services, shared office accommodation, shared emergency operations centres and a suite of shared facilities, as well as enhanced emergency management capabilities and processes for anticipating responses to a range of events. Drawing on arrangements following the earthquakes, several other examples of co-location in this sector are already operational.

5 Cabinet mandates have been given to three chief executives to assume leadership for driving greater cross-government efficiencies and effectiveness. Functional leader mandates relate to three functional areas: property, procurement and information and communication technology (ICT).

6 For a description of BPS results related to improving interaction with government, see: $<$ http://www.ssc. govt.nz/bps-interaction-with-govt>. 
Taken together, these projects (alongside the rebuilding of hospital facilities) represent significant capital investment and a key part of the Christchurch rebuild. A deliberate and coordinated approach to the rebuilding and redesign process is required. The Canterbury Government Leaders Group has built the foundations for ongoing cross-agency coordination. The willingness to try new things in Christchurch means there is scope to test new approaches to service provision, including delivery of BPS results. Christchurch can serve as an innovation zone for BPS, where new models of service delivery and design can be tested, prototypes developed and debugged, and the scalability to the state services assessed.

\section{Embedding Innovation across State Services: From 'innovation by necessity' to 'innovation by design'}

Most of the Christchurch initiatives were 'innovation by necessity'; the status quo was not an option. Christchurch public servants innovated and continue to operate in a difficult and challenging environment. Christchurch can, however, offer lessons about what enables innovation to flourish in a public sector context.

\section{Leadership and Permission are Crucial Enablers of Innovation}

People on the ground in Christchurch could innovate because they had explicit permission from senior leadership to 'do whatever it takes'. The tolerance for risk-taking was higher because the risk of not trying something new was greater, although this was not uniform across agencies (some regional staff had stronger decision rights than others; inconsistent regional boundaries had a further impact on the ability to act without referring to head office).

Permission and clear goals articulated by senior leadership are key enablers of innovation; top-down sponsorship enables bottom-up innovation. A study of high-performing innovative public and private sector organisations and sectors (Albury 2011) concluded that a key characteristic of those organisations is having leadership that is passionate about goals, but is permissive about how to reach them. Innovation is not just a question of unleashing creativity or coming up with bright ideas. 'Innovation by design' requires investment in capability, a focus on users, expertise in the use of innovative methods, as well as strong 
mandates to experiment and to take bounded, informed and well-managed risks. It requires engagement with staff at the front line where new ideas are often generated.

\section{Capability in Innovation Tools and Methods is Essential for Making it Happen}

A number of the Christchurch initiatives were enabled by pre-existing innovation capability and experience in applying innovation tools, methods and disciplines to problems. The Inland Revenue service design team based in Christchurch was instrumental in several of the innovations (in particular, Recover Canterbury and proposals for the shared front of house). Inland Revenue has developed a service design capability over the past seven years. Service design as a method has a strong focus on the customer and their experience as the starting point for designing services, and is a recognised method for driving innovation in the public (and private) sector.

Similarly, the CDHB has established a reputation for investing in innovation. Its overall shared vision was developed through a process that included 'Showcase', a series of participatory workshops and the showcasing of innovative ideas and models of care, involving more than 2000 stakeholders, providers, consumers and health professionals. The earthquakes expedited the implementation of the shared care record, which was in development prior to that time, but the organisational foundations for innovation were well entrenched.

Inland Revenue and the CDHB are exploring the potential to co-locate their service design functions in Christchurch in order to share skills and knowledge. This could provide a prototype to inform the development of some future crossagency innovation capability at the national level. Drawing on these exemplars, the SSC is preparing a case study on innovation capability that will test those organisations against the characteristics derived from the international literature about what makes for an organisation that enables and supports innovation. The intention is for this work to offer lessons to other agencies wishing to enhance their ability to be innovative.

\section{Walking the Talk}

In a small attempt to walk the talk, and inspired by CDHB's Showcase, the SSC decided to try something innovative itself. We decided to forgo the usual cabinet committee briefing process in favour of an experiential session dubbed 'Seismic Shifts' to brief ministers on the initial and emerging Canterbury innovations. The session - something between a trade show and speed dating - involved public servants from Canterbury coming to Wellington to tell their own stories about 
how they had responded to the earthquakes. They used visual props, including videos of users of the innovative services. The timing was such that ministers could choose only four of the eight booths to sit at. A bell was rung at fiveminute intervals, signalling a move to the next booth. On leaving the session, ministers were handed tent cards that subsequently ended up on several of their desks. That two-sided card had messages on each side about how to enable and how to stop innovation (see Box 21.2). A further Seismic Shifts session was held for senior officials. We received positive feedback from minsters about the session. It was a more powerful way of informing them about the Canterbury innovations than a dry paper or briefing from Wellington officials.

\section{Box 21.2}

\section{Seismic Shifts \\ How to stop innovation}

- Demand people think differently and expect it to happen

- Create silos of thinking

- Punish failure

\section{Lessons for fostering transformation}

- Focus on the citizen

- Clear goals, flexible process

- Encourage frontline engagement

\section{The Next Steps}

We need to maintain the enabling environment in Christchurch to keep the momentum of innovation going. Christchurch has the potential to provide a model of twenty-first-century innovative and responsive state services. Agencies are being asked to report to central agencies and ministers about what new things they are trying in Christchurch, including prototyping options for BPS results. We also want to ensure that the lessons from Christchurch are taken elsewhere around the country. That does not mean simply taking a cookiecutter approach to up-scaling initiatives from Christchurch to another part of New Zealand. It means taking the essence of that innovation and grafting it to local conditions. It also means agencies developing their capability to enable and support new innovation, to seek new and better ways of doing things.

The challenge for the centre is to take the lessons from Christchurch to drive BPS work to embed innovation in a business-as-usual context. Canterbury was about disruptive innovation or innovation by necessity. We need to create a seismic shift in activity, behaviour and capability to achieve innovation by 
design. An innovative public sector is one that is agile, responsive and ready for whatever comes its way. Building innovation capability is an important strategy for future-proofing the state.

\section{References}

Albury, D. 2011. 'Creating the Conditions for Radical Public Service Innovation', Australian Journal of Public Administration, 70(3):227-35.

Inland Revenue/Communications and Inquiry National Research Unit. 2011. Inland Revenue and Ministry of Social Development Staff Views of Joined Up Government Service in Christchurch, November (Wellington: Inland Revenue/ Communications and Inquiry National Research Unit). 
This text taken from Future-Proofing the State: Managing Risks, Responding to Crises and Building Resilience, edited by Jonathan Boston, John Wanna, Vic Lipski and Justin Pritchard, published May 2014 by ANU Press, The Australian National University, Canberra, Australia. 